\title{
Effective Utilization of Concrete Sludge as Soil Improvement Materials
}

\author{
Seishi Tomohisa ${ }^{1}$, Yasuyuki Nabeshima ${ }^{1}$, Toshiki Noguchi ${ }^{2}$ and Yuya Miura ${ }^{2}$ \\ 1. Department of Civil Engineering, Akashi National College of Technology, Hyogo 6748501, Japan \\ 2. Department of Architecture and Civil Engineering, Akashi National College of Technology, Hyogo 6748501, Japan
}

\begin{abstract}
The amount of muddy soil generated from various kinds of construction sites is always problematic. It is very difficult to treat muddy soil because of its low strength and high water content. But, the reuse of muddy soil is necessary to reduce the total amount of industrial wastes. Surplus concrete is also in a similar situation. Coarse and fine aggregates are removed from surplus concrete as an intermediate treatment, however, concrete sludge still remains. The authors propose a reuse method that involves the muddy soil being mixed with concrete sludge as an improvement material. The possibility of the utilization of concrete sludge was investigated through laboratory experiments. As a result, it was found that the unconfined compressive strength of the improved soil mixed with concrete sludge increased as the curing proceeded.
\end{abstract}

Key words: Reuse, concrete sludge, muddy soil, improvement material, curing process.

\section{Introduction}

Huge amounts of muddy soil have produced from various kinds of construction sites in recent years. According to the Ministry of the Environment [1], the percentage of sludge to the total amount of industrial wastes accounted for about $44.5 \%$ (about 173,630,000 tons) in 2009 as shown in Fig. 1. Most of these soils are difficult to reuse as a construction material because of low strength and high water content. Surplus concrete is also in a similar situation. Surplus concrete or concrete returned from construction sites are also problematic. The Ministry of Land, Infrastructure, Transport and Tourism [2] have investigated fresh concrete factories and construction companies as to whether surplus concrete was generated or not at their sites, as shown in Fig. 2. Fig. 2 shows that the reduction and reuse of surplus concrete are important issues. Coarse and fine aggregates are removed from surplus concrete as an intermediate treatment, however, a large amount of concrete sludge still remains.

Corresponding author: Yasuyuki Nabeshima, professor, research field: geotechnical engineering. E-mail: nabesima@akashi.ac.jp.
The authors investigated a reuse method of the concrete sludge and discussed using it as a soil improvement material through laboratory experiments. Fresh concrete was dewatered by air drying and crushed into small grains. The crushed concrete sludge was mixed with muddy soil which had high water content and low strength. The unconfined compressive strength of muddy soil improved by mixing with concrete sludge was investigated. The target strength of the unconfined compressive strength was set to 200 $\mathrm{kN} / \mathrm{m}^{2}\left(q_{c}=800 \mathrm{kN} / \mathrm{m}^{2}\right)$ as the second grade of the construction material according to the reuse guidelines of the construction surplus and muddy soils [3]. Combinations of the mixing rate, the grain size and the curing time were investigated to achieve the target strength. The possibility of the utilization of concrete sludge was evaluated through laboratory experiment results.

\section{Experimental Procedures}

\subsection{Materials}

The grain size distribution curves of materials used in this study are shown in Fig. 3. A soft muddy soil was 


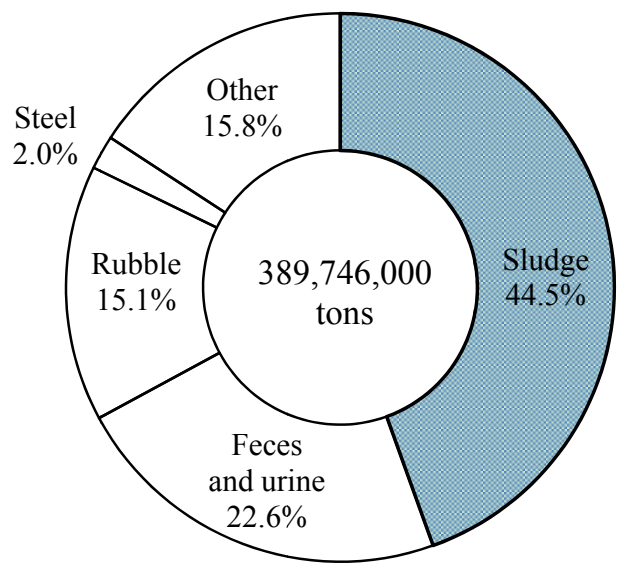

Fig. 1 Amount of industrial wastes in Japan.

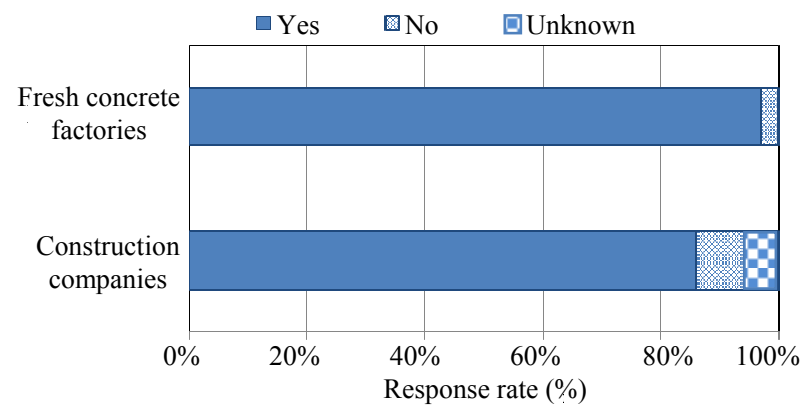

Fig. 2 Questionnaire survey for the state of the surplus concrete.

used as a test soil, GCS (generated concrete sludge) with different grain sizes and BFS (blast furnace slag) were also used as the soil improvement materials.

\subsubsection{Test Soil}

Test soil was taken from the construction site in
Akashi city, Hyogo Prefecture. The soil was difficult to use as a construction material because it had a high water content and low strength. The soil properties are presented in Table 1.

Fig. 4 shows a photograph of a SEM (scanning electron microscope) observation of test soil. This figure confirmed that there were porphyritic textures and granular textures of several micrometers over the entire surface of soil grains.

\subsubsection{Concrete Sludge}

Fresh concrete returned from construction sites was dewatered and pressed with high pressure into a cement cake after the removal of coarse and fine aggregates. In this paper, the cement cake which was dewatered by air drying and crushed into small grains is called "concrete sludge".

In this study, the hardening effect of the concrete sludge is investigated. Model concrete sludge is used to control the hydration time and maximum grain size. Model concrete sludge is artificially made from cement paste with a water-cement ratio of $40 \%$ using ordinary Portland cement. The unconfined compressive strength is discussed just after $8 \mathrm{~h}$ and $48 \mathrm{~h}$ from mixing water and cement, hereafter this is referred to as the hydration time. Also, the cement paste was air-dried for $24 \mathrm{~h}$ and crushed into pieces of up to $5 \mathrm{~mm}$ or $1 \mathrm{~mm}$ in diameter. This is called GCS. GCS is mixed with the test soil in a moist mass ratio of $5 \%$ or $10 \%$.

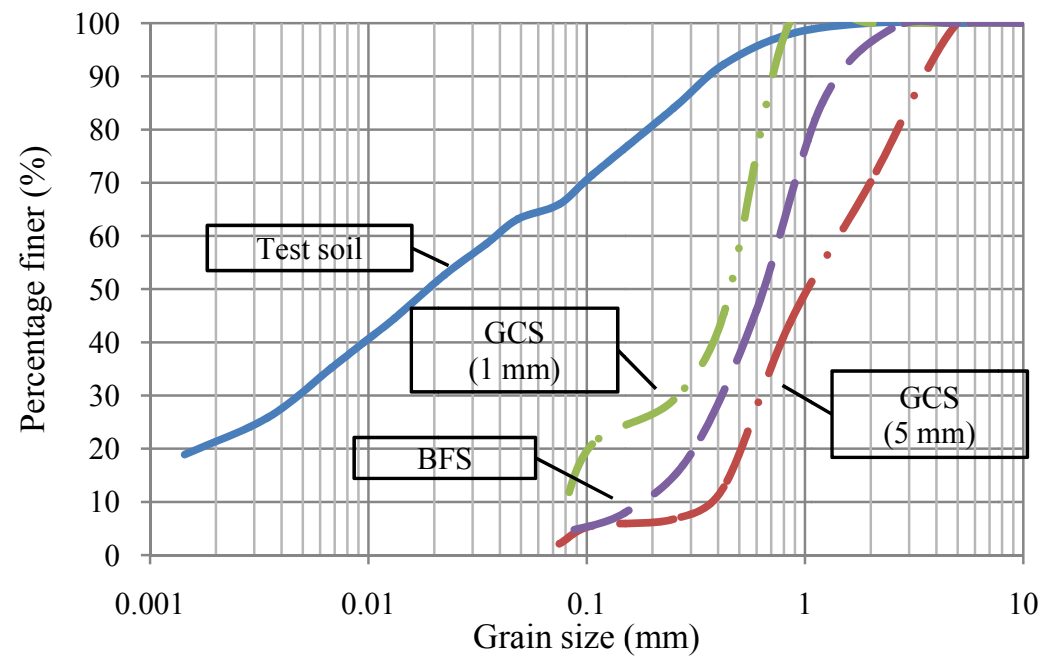

Fig. 3 Grain size distribution curve of materials used in this study. 
Table 1 Soil properties of test soil.

\begin{tabular}{ll}
\hline Properties & Value \\
\hline Water content $(\%)$ & 26.3 \\
Density of soil grain $\left(\mathrm{g} / \mathrm{cm}^{3}\right)$ & 2.62 \\
Liquid limit (\%) & 28.2 \\
Plastic limit (\%) & 16.2 \\
Unconfined compressive strength $\left(\mathrm{kN} / \mathrm{m}^{2}\right)$ & Unmeasurable \\
\hline
\end{tabular}

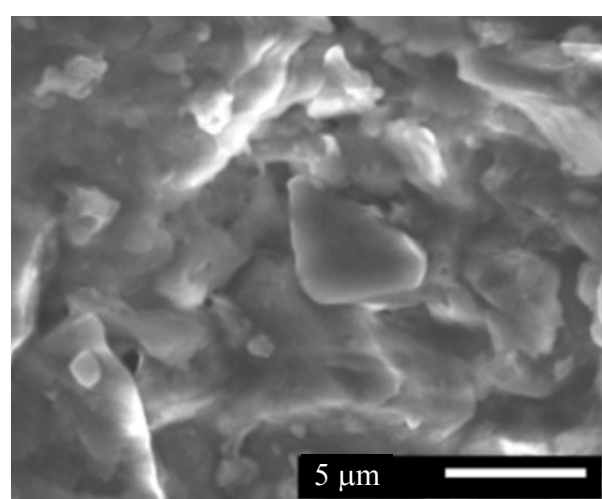

Fig. 4 SEM image of the test soil.

\subsubsection{Blast Furnace Slag}

In the previous studies, it was elucidated that the hardening effect was not observed when GCS was used as a soil improvement material by mixing it with the muddy soil alone $[4,5]$. Therefore, in order to propose the possibility of utilization of concrete sludge as soil improvement materials when combined with other improvement materials, the authors used the BFS to assist the stabilization of the muddy soil. The BFS is a byproduct which is produced by water fracturing through the quick cooling process of the fused steel slag from a blast furnace. It has sharp-edged, amorphous and uniformly sized grains under $5 \mathrm{~mm}$ in diameter and has also the high hardening activity (potential hydraulic property) due to much $\mathrm{CaO}$ and $\mathrm{SO}_{3}$ which are not stable because they solidify without crystallization. BFS is widely used in construction works as construction material and soil improvement additives [6, 7]. In this study, BFS is mixed with the test soil in a moist mass ratio of $5 \%$ or $10 \%$.

\subsection{Sample Preparation}

Sample preparation procedures for the unconfined compression tests were as follows:
(1) Initial water content of the test soil was adjusted and set into $28 \%$;

(2) The mass of the test soil, GCS and BFS were weighed and mixed at the predetermined rates as shown in Table 2;

(3) Cylindrical test specimens were made without compaction according to JGS0821 [8]. Each specimen was $5 \mathrm{~cm}$ in diameter and $10 \mathrm{~cm}$ in height.

Specimens were wrapped in polythene film and cured for 14,28 , and 90 days at a temperature of $20^{\circ} \mathrm{C}$. A series of unconfined compression tests were carried out immediately after the molding and curing. After unconfined compression tests, a SEM observation and an X-ray diffraction analysis were carried out.

Table 2 Sample preparation conditions.

\begin{tabular}{|c|c|c|c|}
\hline $\begin{array}{l}\text { Mixing rate } \\
\text { of BFS (\%) }\end{array}$ & $\begin{array}{l}\text { Mixing rate of } \\
\text { GCS }(\%)\end{array}$ & $\begin{array}{l}\text { Maximum grain } \\
\text { size }(\mathrm{mm})\end{array}$ & $\begin{array}{l}\text { Hydration } \\
\text { time (h) }\end{array}$ \\
\hline \multirow{9}{*}{0} & 0 & - & - \\
\hline & \multirow{4}{*}{5} & \multirow{2}{*}{1} & 8 \\
\hline & & & 48 \\
\hline & & \multirow{2}{*}{5} & 8 \\
\hline & & & 48 \\
\hline & \multirow{4}{*}{10} & \multirow{2}{*}{1} & 8 \\
\hline & & & 48 \\
\hline & & \multirow{2}{*}{5} & 8 \\
\hline & & & 48 \\
\hline \multirow{9}{*}{5} & 0 & - & - \\
\hline & \multirow{4}{*}{5} & \multirow{2}{*}{1} & 8 \\
\hline & & & 48 \\
\hline & & \multirow{2}{*}{5} & 8 \\
\hline & & & 48 \\
\hline & \multirow{4}{*}{10} & \multirow{2}{*}{1} & 8 \\
\hline & & & 48 \\
\hline & & \multirow{2}{*}{5} & 8 \\
\hline & & & 48 \\
\hline \multirow{9}{*}{10} & 0 & - & - \\
\hline & \multirow{4}{*}{5} & \multirow{2}{*}{1} & 8 \\
\hline & & & 48 \\
\hline & & \multirow{2}{*}{5} & 8 \\
\hline & & & 48 \\
\hline & \multirow{4}{*}{10} & \multirow{2}{*}{1} & 8 \\
\hline & & & 48 \\
\hline & & \multirow{2}{*}{5} & 8 \\
\hline & & & 48 \\
\hline
\end{tabular}




\section{Results and Discussion}

\subsection{Strength and Curing Period}

Fig. 5 shows the relationship between the unconfined compressive strength and the mixing rate of GCS. The maximum grain size of GCS is $1 \mathrm{~mm}$ and the hydration time is $8 \mathrm{~h}$.

The unconfined compressive strength of specimens which cured for 0 day, meaning without curing, began to increase immediately after being mixed with GCS. This may be due to the grain size improvement and drops of water content by mixing GCS because of the lack of hardening time. In all test cases of 14 days and 90 days, unconfined compressive strength increased as the mixing rate of GCS increased due to the hardening effect of GCS. And, this tendency is clear with respect to the increase in the mixing rate of BFS. Therefore, it was suggested that the hardening effect of BFS was larger than that of GCS.

\subsection{Strength and Maximum Grain Size}

Fig. 6 shows the relationship between the unconfined compressive strength and the maximum grain size. The mixing rate of BFS was $10 \%$ and the hydration time was $8 \mathrm{~h}$.

The unconfined compressive strength of improved soil that was mixed with the maximum grain size of $1 \mathrm{~mm}$ of GCS was larger than that with a maximum grain size of $5 \mathrm{~mm}$. This tendency becomes more obvious with increases of curing days and the mixing rate of GCS. In the case, in which the improved soil was mixed with GCS $10 \%$ and BFS $10 \%$ and cured for 90 days, the unconfined compressive strength mixed with $1 \mathrm{~mm}$ maximum grain size of GCS was double of the $5 \mathrm{~mm}$ one. So, it is shown that making a smaller maximum grain size is effective for the hardening activity. The specific surface of $1 \mathrm{~mm}$ of GCS was larger than that of $5 \mathrm{~mm}$, and the hardening effect of 1 mm was effective.

\subsection{Strength and Curing Time}

Fig. 7 shows the relationship between the unconfined compressive strength and the curing time. The maximum grain size is $1 \mathrm{~mm}$.

In the case in which BFS was mixed alone with test soil, unconfined compressive strength increased a little

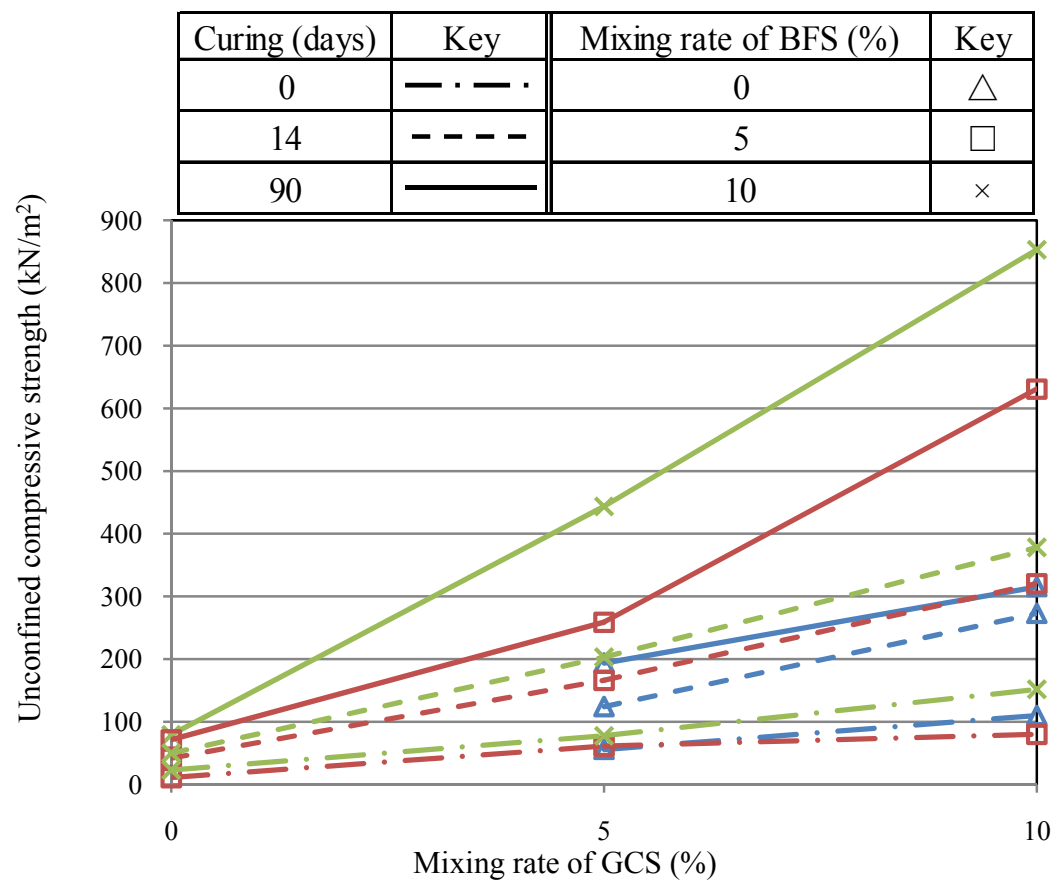

Fig. 5 The unconfined compressive strength and the mixing rate of GCS (maximum grain size: $1 \mathrm{~mm}$, hydration time: $8 \mathrm{~h}$ ). 


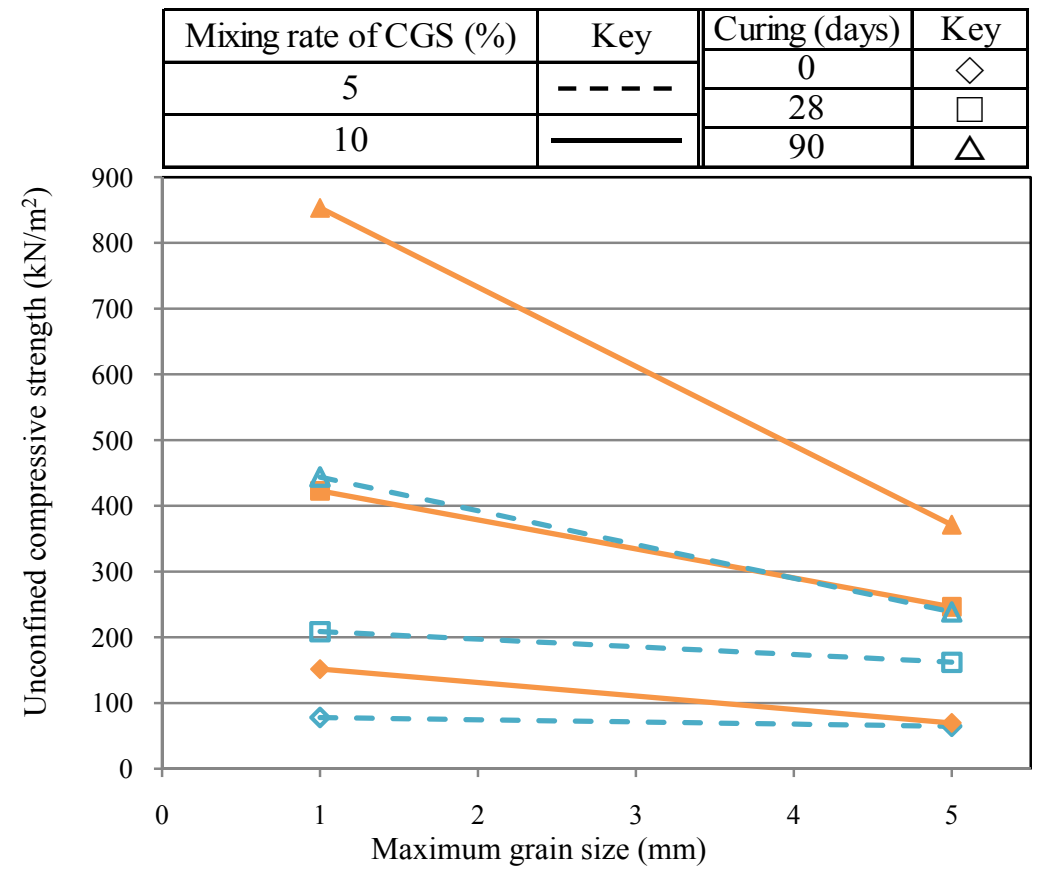

Fig. 6 The unconfined compressive strength and the maximum grain size (mixing rate of BFS: 10\%, hydration time: $8 \mathrm{~h}$ ).

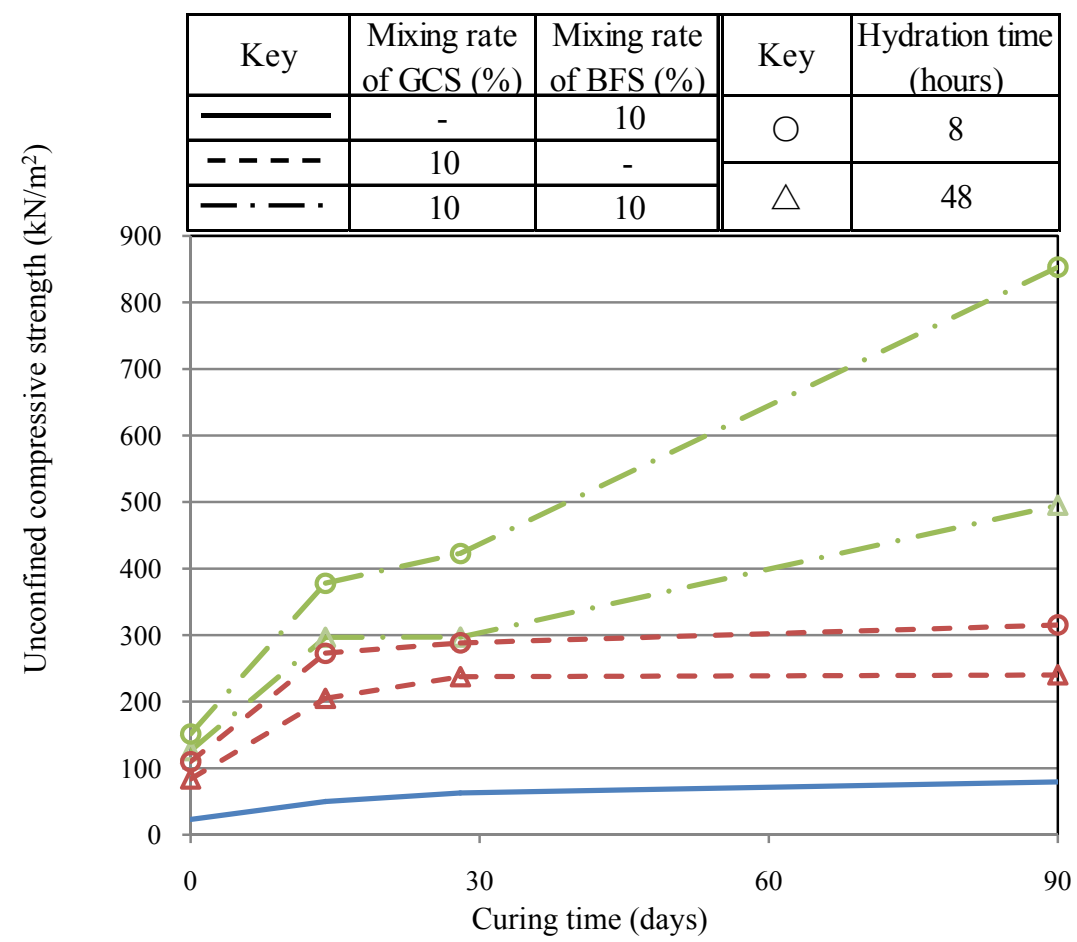

Fig. 7 The unconfined compressive strength and the curing time (maximum grain size: $1 \mathrm{~mm}$ ).

after 90 days of curing time. This is derived from the fact that the potential hydraulic property was not shown well because there was no alkali stimulation in the improved soil. The unconfined compressive strength increased between 0 day and 14 days of the curing time in the case in which $10 \%$ GCS was mixed alone. This is because the strength increased at the early stage of hardening. However, after 14 days of curing time, the strength did not change so much. The unconfined compressive strength mixed with both GCS and BFS 
rapidly increased from 0 day, and also increased after 14 days of curing time. The long-term increase in unconfined compressive strength was due to the hydraulic property of BFS which was larger than the hardening effect of cement sludge. From these tendencies, it was explained that the hydration ability of cement sludge terminated within 14 days and blast furnace slag needed long-term curing to show its potential hydraulic property.

A $200 \mathrm{kN} / \mathrm{m}^{2}$ target strength was attained after a 14-day curing of improved soil that was mixed with the GCS and BFS together.

\subsection{Hardening Reaction Products}

\subsubsection{X-ray Diffraction Analysis}

$\mathrm{X}$-ray diffraction analysis was used to analyze the hardening reaction products for the improved soil mixed with BFS $10 \%$ and GCS $10 \%$ (maximum grain

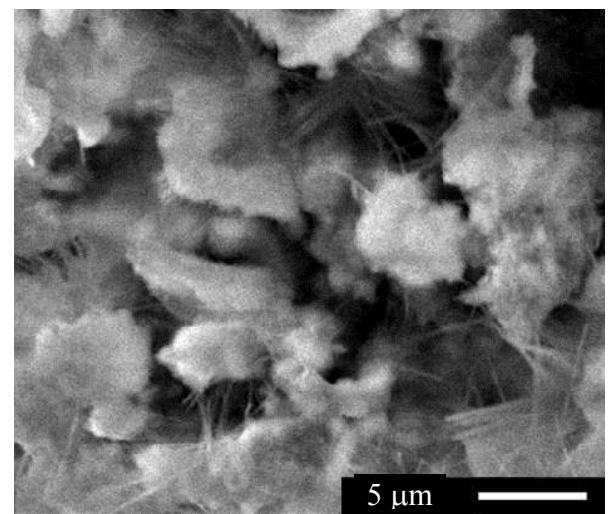

Fig. 8 SEM images of GCS in the improved soil (hydration time: $8 \mathrm{~h}$, curing: 1 day).

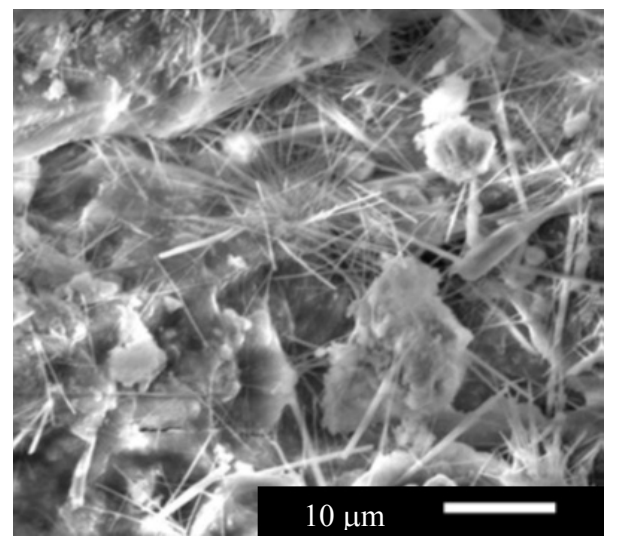

Fig. 9 SEM images of improved soil mixed with GCS and BFS (hydration time: 8 h, curing: 1 day). size: $1 \mathrm{~mm}$, hydration time: $8 \mathrm{~h}$ ) which was the most effective mixing ratio between BFS and GCS. However, hardening reactants like ettringite were not observed in this result [5].

\subsubsection{Scanning Electron Microscope Observation}

Figs. 8 and 9 show the results of scanning electron microscope observations.

Fig. 8 shows an electron microscope image of the improved soil that was mixed with GCS with a hydration time of $8 \mathrm{~h}$. Calcium reactants can be seen on the surface of the soil particle. And, thin needle-formed ettringite reactants can be seen in the voids between soil particles.

Fig. 9 shows an electron microscope image of the improved soil that was mixed with both BFS and GCS with a hydration time of $8 \mathrm{~h}$. Many thick needle-formed ettringite reactants can be seen. The length of reactants was from several micro meters to $20 \mu \mathrm{m}$. They were remarkably observable in comparison with Fig. 8.

\section{Conclusions}

The authors have proposed a reuse method of the surplus concrete sludge as a soil improvement material. Unconfined compressive strength and hardening mechanisms of test soil mixed with GCS and BFS were investigated. The main conclusions are as follows:

(1) The improved soil had higher strength as the maximum grain size of GCS became smaller, the hydration time was shorter, and the mixing rate was larger;

(2) In early-term curing, grain size improvement and drops of water content by mixing GCS contributed to the strength development. In long-term curing, the hydration ability of GCS and potential hydraulic property of BFS contributed to the strength development;

(3) In the case of curing for 14 days and using GCS which has a maximum grain size of $1 \mathrm{~mm}$ and the hydration time of $8 \mathrm{~h}$, the target strength was attained by mixing in 5\% GCS and 5\% BFS together;

(4) Hardening reactants can be seen in the improved 
soil that was mixed with both BFS and GCS through the scanning electron microscope observations.

\section{Acknowledgments}

The authors would like to express thanks to graduated student, Saki Yasui and associate professor John Herbert of Akashi National College of Technology for helping with the writing, reviewing and improving of this paper.

\section{References}

[1] Ministry of the Environment Home Page, http://www.env.go.jp/recycle/waste/saVngyo/sangyo_h21. pdf (accessed Dec. 19, 2011). (in Japanese)

[2] Ministry of Land, Infrastructure, Transport and Tourism Home Page, http://www.zai-keicho.or.jp/pdf/research/ 1062.pdf (accessed Dec. 19, 2011). (in Japanese)

[3] Construction Sludge Utilization Manual, Technical Note of PWR, No. 3407, Public Works Research Institute, 1996, p. 58. (in Japanese)

[4] S. Yasui, Effective utilization of concrete sludge as ground improvement material, in: Proceeding of Geo-environmental Engineering, Takamatsu, 2011, pp. 169-172.

[5] T. Noguchi, Y. Miura, S. Tomohisa, Y. Nabeshima, N. Naito, S. Yasui, Effective utilization of concrete sludge as soil improvement additives, in: Proceedings of the 10th National Symposium on Ground Improvement, Kyoto, 2012, pp. 487-492. (in Japanese)

[6] Water-Granulatedblast Furnace Slag, Technical report, Nippon Slag Association, 2009. (in Japanese)

[7] H. Matsuda, N. Kitayama, K. Takamiya, T. Murakami, Y. Nakano, Study on granulated blast furnace slag applying to the ground improvement, Journal of the Japan Society of Civil Engineers 764 (2004) 85-99. (in Japanese)

[8] Practice for Making and Curing Stabilized Soil Specimens without Compaction, Test Procedures and Manuals for Geotechnical Materials, Japanese Geotechnical Society, 2009, pp. 426-434. (in Japanese) 